\title{
Patrick Henry Winston - Two Reflections
}

\author{
Kenneth D. Forbus, Mark A. Finlayson
}

Former president of the Association for the Advancement of Artificial Intelligence, and professor at the Massachusetts Institute of Technology Patrick Henry Winston, died July 19, 2019. In this article, former students Kenneth D. Forbus and Mark A. Finlayson provide personal reflections on Winston and the impact he had on their lives and careers.
$\mathrm{P}$ atrick Henry Winston died July 19, 2019 in Boston, Massachusetts. A professor at the Massachusetts Institute of Technology (MIT) for almost 50 years, Patrick Winston was director of MIT's Artificial Intelligence Laboratory from 1972 to 1997 before it merged with the Laboratory for Computer Science to become MIT's Computer Science and Artificial Intelligence Laboratory. Winston led the Computer Science and Artificial Intelligence Laboratory's Genesis Group, which focused on developing artificial intelligence (AI) systems that have humanlike intelligence, including the ability to tell, perceive, and comprehend stories. He believed that such work could help illuminate aspects of human intelligence that scientists don't yet understand. Outside of the laboratory he also cofounded Ascent Technology, which produces scheduling and workforce management applications for major airports. Most of all, however, Winston's favorite activity was teaching, for which he was honored with the Baker Award, the Eta Kappa Nu Teaching Award, and the Graduate Student Council Teaching Award. Patrick Winston served as president of the Association for the Advancement of Artificial Intelligence from 1985 to 1987. In this brief article, former students Kenneth D. Forbus and Mark A. Finlayson provide personal reflections on the mark Winston had on their lives and careers. 


\section{A Recollection \\ by Kenneth D. Forbus}

I first met Patrick when I started working at MIT's Artificial Intelligence Lab in Fall of 1973. I was a freshman, doing a project with David Marr that was a step on the path to the Primal Sketch. It was like a dream come true to work there. At the time, Patrick had just taken over as director, despite being an assistant professor. This was an unusual burden, but he handled it well, ensuring that it ran more smoothly while maintaining an exciting intellectual environment.

Patrick taught 6.034, Introduction to Artificial Intelligence, for many years. He was awesome, a rare combination of extremely organized and inspiring. In 1973, there were no personal computers and most students had no regular access to computers at all. This meant that programming assignments were mostly done via hand-simulation. A defining feature of 6.034 was multiday take-home exams. These were brutal and sometimes fiendishly difficult. For example, a question on symbolic mathematics asked about a hypothetical procedure MathEQ, which would return it if the two expressions provided as arguments were equivalent, or nil otherwise. One part of the question asked us to attempt to write MathEQ. Another part asked us to explain why MathEQ is "something that you don't want." Because writing MathEQ would be equivalent to solving the Halting Problem, this was of course impossible. To be fair, they did suggest that we not try to spend too much time trying to write MathEQ. To those of us who had yet to take an algorithms course, working on this problem was quite a learning experience.

Patrick also had a wicked sense of humor. At the end of the take-home exam, the staff provided beer for the students. In 1973 there were five questions, with boxes on chairs labeled one to five to accumulate answers to each part. (No computers, remember, assignments were turned in on paper, commonly hand-written.) Patrick asked me if I had any scratch paper. He and the teaching assistants then stapled it together, to look like a stack of answers, and put it in another box on a chair labeled as "six." Thus the hack was set. The next student who came in confidently added his answers to the first five piles. On seeing the extra chair, he stared at it for a moment, and then in a quavering voice, repeatedly asked "six?" getting increasingly alarmed. The teaching assistants calmed him down with some beer, and the joke continued until the pile in the chair marked "six" was clearly much smaller than the rest. This sense of humor extended well outside of class. Patrick looked young, and sometimes passed himself off as a graduate student to unsuspecting visitors, or as his own secretary. He would sometimes commiserate with students coming in to see him, pretending that he, too, was waiting for Professor Winston to arrive, and agreeing with their complaints about him.

Patrick was an incredible mentor, as I found out when he became my undergraduate advisor. He was

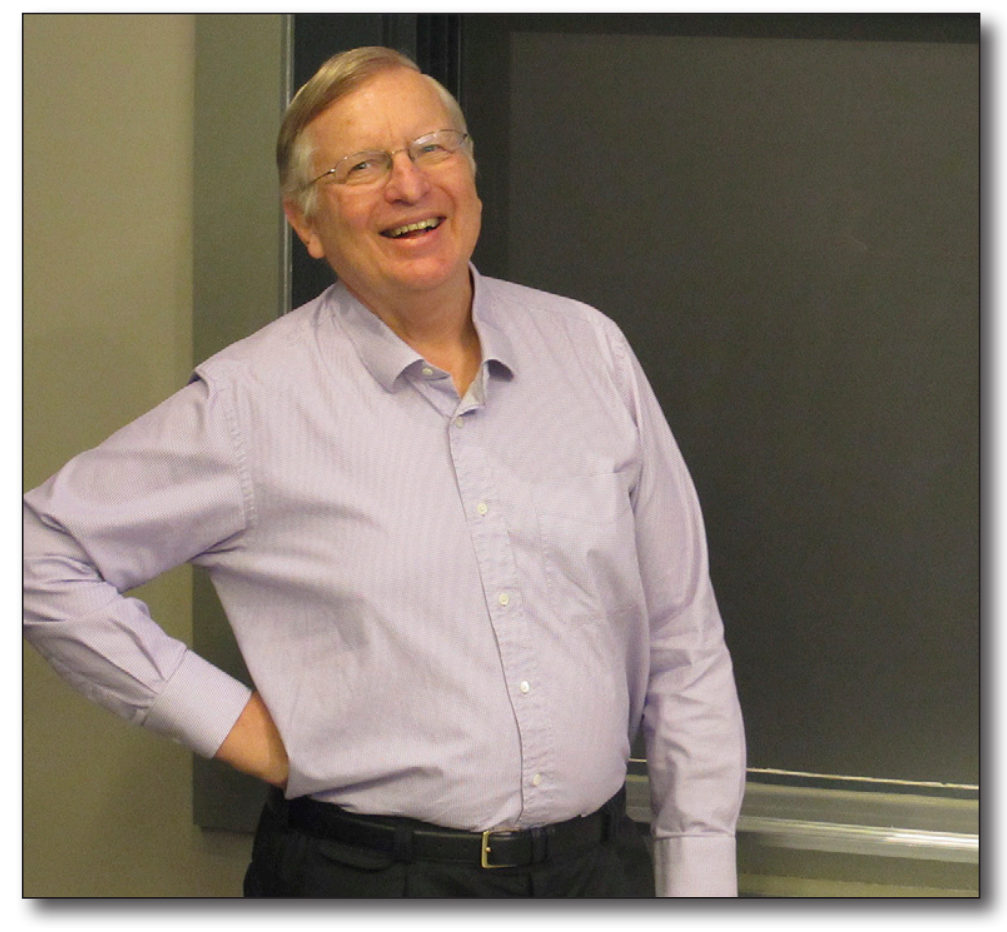

Patrick Henry Winston at the Massachusetts Institute of Technology.

Photograph courtesy of Massachusetts Institute of Technology.

always supportive of his advisees, especially when things got tough. Although Gerald Sussman was my thesis advisor, I continued to learn from Patrick in graduate school. The laboratory ran on the Defense Advanced Research Projects Agency umbrella funding in those days, and Patrick was a master at writing proposals. I contributed to two of those proposals as a graduate student, and what I learned from Patrick in this process has been invaluable throughout my career.

Patrick's thesis and his subsequent work were landmarks in research on analogy. His idea of nearmisses, where a trainer uses their understanding of a learner's concept to select examples that will be easier to learn from, is very important both for analogical learning and for active learning more generally. He was the first to explore several algorithms for analogical matching and to use simplified English to automatically produce representations for his system to use. Tragically, his thesis code did not survive due to the technology limitations of the day. Disk space was scarce, so an automatic program, the Grim File Reaper, deleted files that hadn't been touched after some period of time. The expectation was that such files could be restored from backup magnetic tapes. Unfortunately, those tapes were expensive as well, and so they were reused instead of archived. Thus many programs from that era are now lost forever.

Patrick's dedication to the AI enterprise showed through all of his thinking. At one point he raised a raccoon that had been abandoned by its mother, which caused him to reflect on the relative intelligence 
of people and other creatures. A raccoon, he noted, seems unlikely to be smart enough to think of making an artificial raccoon. While humans are definitely smart enough to think of building AIs, whether we are smart enough to do it remains an empirical question at this stage of the field. Patrick was one of those pioneers who kept his eye on the big questions, and conveyed his enthusiasms through all his works. He is missed.

\section{In Memoriam by Mark A. Finlayson}

"What do you say?" Patrick's enunciated greeting would ring out, ritual-like, as I presented myself at the threshold to his office, 32-251. His blond hair poking up from behind his monitor, I could hear in his voice whether he wore his characteristic wry smile. My visits were unscheduled: I would come over from my neighboring office when I saw his light on and door open. I spoke with him almost every workday for nearly twelve years, in conversations long and short, mostly about research: science, engineering, academics, AI, cognition, or the latest paper or proposal we were writing. But we also ranged widely over topics personal and public. Now that I am a time-pressed faculty member myself, I am increasingly amazed to recall his patience at my demands on his time. Despite sometimes him growling "Go away!" in mock anger (which meant he was working toward an impending deadline), he would almost always finish what he was doing and give his undivided attention. He became my touchstone for issues large and small, and the longer I spent with him, the more I marveled at the gems of wisdom contained in even the most minor discussions.

I first presented myself at Patrick's door in the Spring of 2003, a young, intellectually lost doctoral student (and it was Patrick, not Pat - the latter was a woman's name, he would say). I was casting about for where to go next, and I wasn't sure that next stage involved a PhD at all. But I conceived an interest in studying cognition and society from a computational point of view, and after a string of almost random connections, found myself at Patrick's door. He told me, in no uncertain terms, that he was on the "lunatic fringe" of AI, and that I should go work with Tom Knight instead, whose work in synthetic biology was really going somewhere. Nobody was interested in Patrick's stuff; there was no funding.

As it turned out, there was funding - a lot of it; and there was a lot of interest, too. But that didn't matter so much to me at the time, because in Patrick I had found exactly what I was looking for: Not only a research advisor, working on fascinating science and driven by deep and important questions, but, more importantly, a mentor who would deliberately drive my intellectual and moral development. Someone who would challenge me, whom I could emulate, who would train me to think better and be better. Patrick was continuously thinking, synthesizing, exploring for a more unified perspective. He was driven by an inspiring vision, to understand the computational nature of human intelligence. He sought principles, and he was continuously on the lookout for the next powerful idea. He was a master communicator, orator, and teacher, with a genuine sense of humor and an ear for startling and effective turns of phrase. And he was also a captivating storyteller who used his own experiences, told with rich detail, to drive home his ideas and his lessons.

Just as importantly, however, Patrick was also deeply honest and morally steadfast, with a profound dedication to service. He was an MIT lifer, and when asked to introduce himself at professional gatherings, he would sometimes jokingly offer: "Hello, I'm Patrick Winston, at MIT. Before MIT, I was in high school." He believed MIT was an institution that served a noble purpose for the nation and the world, and believed it should be held to a higher standard. He wasn't afraid to criticize its leaders when he thought they had strayed. These convictions - the combination of moral clarity, sense of purpose, and scientific vision - made a deep impression on many in his orbit. I was no exception. When I left MIT in 2014 to continue in academe, Patrick's inspiration and example stayed with me as an irreplaceable lodestar.

We communicated frequently even after I left MIT. He remained vigorous to the last, pursuing his research and teaching 6.034 to hundreds of students. A week before he died, on his sickbed yet expected to recover, speaking in barely a whisper due to weakness, he was instructing his newest doctoral student on the project he had for her. It was characteristic, him thinking and planning to the end, dying, as he would say, "with his boots on." I had a list of questions waiting for when he recovered: There was still so much to learn, and it's hard to imagine him not there to learn it from.

I was privileged and fortunate to have sat at his feet for a dozen years. He was a singular and irreplaceable mentor, gone much too soon, and I will miss him dearly. I say: Thank you for everything, and safe travels, my friend.

Kenneth D. Forbus is the Walter P. Murphy Professor of Computer Science and Professor of Education at Northwestern University. He received his degrees from the Massachusetts Institute of Technology (PhD in 1984).

Mark A. Finlayson is the Eminent Scholar Chaired Assistant Professor of Computer Science in the School of Computing and Information Sciences at Florida International University in Miami, Florida. He received his PhD under Patrick Winston's supervision in 2012. 